\title{
On brongniardite, a new mineral
}

\section{M.A. Damour}

To cite this article: M.A. Damour (1850) On brongniardite, a new mineral, Philosophical Magazine Series 3, 36:245, 477-479, DOI: 10.1080/14786445008646526

To link to this article: http://dx.doi.org/10.1080/14786445008646526

$$
\text { 册 Published online: } 30 \text { Apr } 2009 .
$$

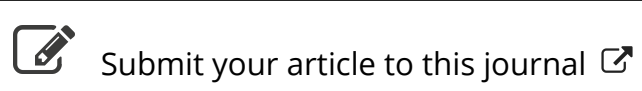

\footnotetext{
Џll Article views: 3
}

Q View related articles $\asymp$ 
the sword-shaped sign that was seen over Jerusalem at the commencement of the war which ended in the destruction of the Holy City by Titus may have been the comet of Halley.

The most ancient, and at the same time one of the most certain apparitions of this body, took place in the year 11 B.c., reckoning according to the manner of astronomers. It was observed, accurding to Dion Cassius, under the consulate of M. Messala Barbatus and P. Sulpicius Quirinus, before the death of Agrippa, and seemed as though it were suspended over the city of Rome. 'The Chinese found it on the 26th of August in Gemini; it passed over this constellation, north of Castor and Pollux, towards Leo and Virgo, moving at the rate of $6^{\circ}$ daily. Subsequently it passed near Arcturus and other stars in Boötes, and arrived in Ophiuchus and Serpens. Fifty-six days after, August 26, it set with $\pi$ and $\sigma$ Scorpii.

After the publication of M. Biot's valuable details in the appendix to the Connaissance des Temps for 1846, I attempted an orbit for this comet, and was immediately struck with the similarity of the elements to those of the comet of Halley. The only alteration necessary appeared to be a diminution of the orbital inclination, which, instead of $17^{\circ}$, would be more satisfactory at $8^{\circ}$ or $10^{\circ}$. The Chinese description cannot be strictly followed, or we should have a very irregular path; but I am satisfied that the elements of Halley's comet for perihelion, node and least distance, and an inclination of $8^{\circ}$, will accord as well with the observations as any orbit can possibly do.

Previous to the year 11 B.c. the accounts of comets become so vague that it would be vain to attempt to carry the inquiry into more remote antiquity. I think it will be deemed a fact of considerable interest that the celebrated comet which bears the name of our countryman Halley may be traced, in a pretty satisfactory manner, as far back as the year 11 before the Christian æra. For this extensive knowledge of its probable history we are mainly indebted to the records preserved in the annals of the various reigning dynasties in China.

\section{Intelligence and Miscellaneous Articles.}

ON BRONGNIARDITE, A NEW MLNERAL. BY M. A. DAMOUR.

M CASTELNAU, during his last journey in America, collected V. a considerable number of mineral substances, which he deposited with M. Damour to examine. Among these minerals, there was a large specimen possessing metallic lustre, and described as an ore of silver. As it did not possess any trace of crystallization, it was only by analysis that it could be ascertained to be a distinct species, consisting essentially of sulphur, antimony, lead and silver. Its principal characters are these :-It has the metallic lustre peculiar to the antimonio-sulphurets, such as polybasite, bournonite, zinkenite, \&c. Its fracture is uneven, and it has no cleavage. Its powder blackish- 
gray. It scratches calcspar, and is scratched by a steel point. Its density is 5.950 . When heated on charcoal, it decrepitates, and quickly fuses at a temperature below incipient redness, emitting a sulphurous smell and white vapours. After long-continued roasting, it leaves a globule of silver surrounded by a yellow aureola, indicating the presence of oxide of lead. When heated in a close glass tube, it decrepitates, fuses, and yields a small orange-red sublimate, surmounted by a white sublimate. If heated in an open glass tube, it decrepitates, fuses, disengages a strong sulphurous odour, and a white sublimate of peroxide of antimony is deposited on the sides of the tube.

Concentrated nitric acid attacks it rapidly, with the evolution of nitrous vapours; the silver dissolves, and a residue is left, formed of sulphur, oxide of antimony and sulphate of lead. Nitric acid, diluted with four times its volume of water, attacks it slowly, evolving sulphuretted hydrogen; the silver and lead are partially dissolved; a gray deposit is left, in small needles, consisting of sulphuret and oxide of antimony, containing a considerable portion of lead and silver.

Hydrochloric acid, when concentrated and boiling, dissolves this substance completely, evolving sulphuretted hydrogen. On cooling, the solution becomes turbid, and deposits chloride of silver mixed with chloride of lead.

A boiling solution of caustic potash attacks this mineral when finely pulverized. It thus dissolves a large quantity of sulphuret of antimony; a black heavy powder remains, which consists of sulphuret of silver and lead containing some antimony.

If eulphur be added to the potash solution, the greater part of the antimony may be separated by successive decantations; the author, however, never succeeded by this method in separating the sulphurets of lead and silver perfectly from the sulphuret of antimony.

The analysis of the mineral was performed by acting upon it with a current of dry chlorine, in the manner described by M. Rose. The volatile chlorides of sulphur and antimony were separated by exposure to a gentle heat from the fixed chlorides of silver and lead. 'The sulphur was converted into sulphuric acid, and its quantity deduced from that of the sulphate of barytes which it yielded; the antimony was precipitated by sulphuretted hydrogen; the sulphuret obtained was analysed by the direct determination of the sulphur, and inferring the antimony.

The fixed chlorides were treated with boiling water, which dissolved the chloride of lead; the chloride of silver remained insoluble; its weight indicated the proportion of silver; the chloride of lead was converted into sulphate, and the weight of it gave that of the lead.

The liquor separated contains a minute quantity of copper, iron and zinc, the quantity of which was ascertained by the usual processes.

The mean of three analyses gave- 


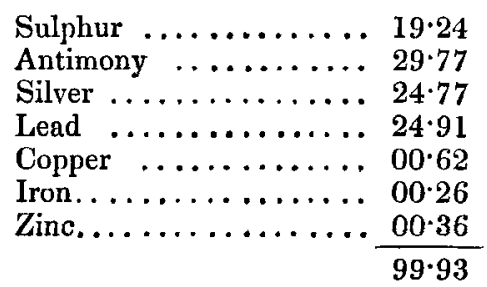

The above results indicate the constitution of the mineral to be 5 equivs. sulphur, 2 equivs. antimony, 1 equiv. silver, 1 equiv. lead. In composition it approaches the schilfylaserz, described in Dufrenoy's Mineralogy, containing, according to Wöhler, -

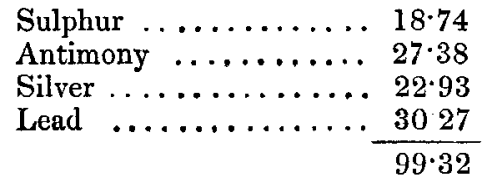

Considerable difference in the composition of these two substances is however observable; the crystallographical characters of the schilfglaserz serve to distinguish one from the other; in fact, the latter mineral crystallizes in the system of the right rhombic prism, and gives well-marked cleavages; whilst the new mineral has a shining uneven fracture, without any indication of cleavage. It is to be expected, however, that it will at some time be found in regular crystals.

The specimen brought by $M$. Castelnau comes from the Mexican mines, and weighs about 14 lbs. One of its surfaces is sprinkled with iron pyrites. From its size and appearance it may be presumed to form a workable seam.

M. Damour proposes for this substance the name of brongniardite, as a tribute of respect to the memory of the late M. Brongniart.Annales des Mines, vol. xvi. p. 227.

\section{ACTION OF SULPHATE OF MAGNESIA AND SULPHATE OF ZINC.}

M. Schaeuffele states, that when a saturated solution of sulphate of magnesia is put in contact with pulverized sulphate of zinc, the salt obtained differs from that procured by the inverse operation. In the first case the crystals contain 12.59 per cent. of magnesia and $11 \cdot 60$ of oxide of zinc, whilst in the second case the quantities are 27.84 of oxide of zine and only 0.27 of magnesia.

The same fact is observed with regard to sulphate of iron in com. bining with sulphate of zinc. If the first of these salts be taken in powder, and the second in saturated solution, the crystals of the double salt obtained contain 13.80 per cent. of oxide of zinc and 12.10 of oxide of iron; whilst, on the contrary, if a saturated solution of sulphate of iron be taken, and the sulphate of zinc in powder, the double salt formed contains $14^{\circ} 63$ of oxide of iron and 12.05 only of oxide of zinc. 